\title{
APPLICATION OF CURRENT DIFFERENTIAL PRINCIPLE IN THE DETECTION OF ENERGY THEFT IN A GSM-BASED SINGLE-PHASE SMART METER
}

\author{
${ }^{1 *}$ Samson Oladayo Ayanlade and ${ }^{2}$ Daniel Taiwo Sawyer \\ ${ }^{1}$ Dept. of Electrical and Electronic Engineering, Lead City University, Nigeria. \\ ${ }^{2}$ Dept. of Electronic and Electrical Engineering, Obafemi Awolowo University, Nigeria. \\ ${ }^{*}$ Corresponding Author
}

DOI: https://doi.org/10.51193/IJETSI.2021.6402

\begin{abstract}
This study, based on current differential principle, developed a GSM-based Single-phase smart meter with the detection of energy theft due to meter bypassing and tampering. These were with a view to improving and reducing the distributed energy losses in distribution system and to minimize loss of revenue in the Nigeria power distribution industry. The smart meter unit was developed using various discrete components to measure energy usage, control the connection of the user remotely (connection and disconnection) and also to communicate with the utility and the consumer's meter. The communication link between the consumer's meter and Power Distribution Company were established with the aid of GSM module. The results obtained from the study showed $87 \%$ system efficient and the energy meter has a capacity of measuring minimum and maximum load current of $0.002 \mathrm{~A}$ and $40 \mathrm{~A}$, respectively.
\end{abstract}

Keywords: Current Differential Principle, Energy Theft, Power Quality, Power loss and Smart meter.

\section{INTRODUCTION}

Electricity is commonly used in contemporary culture because it increases productivity and enhances the living condition in the daily lives of human [1]. In Nigeria, [2] sets the power delivery frequency to be $50 \mathrm{~Hz}$. Domestic, commercial and industrial loads are operated by electricity. Energy meter is used to measure the amount of energy consumed by the loads. Bills accuracy for the consumer is generated by the meter. [3]. Over the years, different types of energy measuring meters have evolved, from the electromechnical meter to the smart meter with 


\section{International Journal of Engineering Technology and Scientific Innovation}

ISSN: 2456-1851

Volume: 06, Issue: 04 "July-August 2021"

the purpose of attaining best and efficient solutions for energy conservation etc. [4]. Worldwide, power distribution companies are faced majorly with low billing and energy theft [5]. Different non-technical and technical techniques in recent past have been proposed to detect energy theft [5-8] The non-technical method employed was the investigation of the consumers with vary load-profile while for the technical methods, harmonic generator, extreme learning machine techniques, among others were adopted to detect energy theft in distribution systems. For the various technical methods to be implemented effectively, a good communication system must be ensured. [12-14]. Smart meter emerged the best among other schemes reviewed for the controlling of energy theft, considering the efficiency, reliability of the system, and economy cost, Thus, it led to the innovation of smart meter which is of great importance to this study [9]$[10]$.

Studies in this area have been carried out using different methods in detecting energy theft such as [11] in their work designed a wireless electricity theft detection and monitoring system using AT89S52/C51 microcontroller, relays, opto-couplers, precaution module, etc. Ref. [12] designed a smart meter using Atmega328p microcontroller, Hall effect sensor and ZigBee module. Ref. [13], in their work designed a tampering detection energy meter. The limitation of their work was the lack of disconnecting the supply to the load by power utility through SMS in case of tampering. In other research $[14,15]$, in their work using the power line impedance technique to determine the location of an illegal tapping at the feeder Similarly, an energy theft detection system in [16] was designed to detect an illegal tapping on distribution lines, among others. These existing methods however involve the simulation of the designed system which was not implemented. This paper presents an effective method, which uses current differential principle to determine energy theft due to bypassing and tampering to improve the power quality and reduce revenue loss in distribution systems.

\section{METHODOLOGY}

\subsection{Current Differential Principle}

The magnitude of current in the live wire which is denoted as $I_{L}$ and that in the neutral wire which is denoted as $I_{N}$ must be equal and opposite in direction such that the algebraic sum of the two current is zero as depicted in Equation (1). Under operating normal condition, the current in the live wire, which is denoted as $I_{L}$ and the neutral which is denoted as $I_{N}$ must be equal. In the case of an energy theft, the magnitude of the two currents won't be the same and as a result the algebraic sum will not be equal to zero. A tolerance value of $0.20 \mathrm{~A}$ was chosen for the difference due to various smart meter components such as the transformer, relay and other discrete components that consume power. 


$$
I_{L}-I_{N}=0
$$

\subsection{System Design}

The three functional units of the smart metering system were designed to have the smart metering unit, energy theft detection unit and communication channel unit. The smart metering unit was developed for the connecting and disconnecting of the consumer's electricity supply, measuring the consumption of power usage; energy theft detection unit, which has two ACS-712 current sensors, and while light dependent resistor (LDR) for the detection of energy theft on the meter based on by-pass and tampering and display the information on a LED display board. The channel unit has a GSM module that communicates with the smart metering unit and was also responsible for the signal transfer of energy theft by the consumer to the power distribution company. The block diagram of the smart meter is presented in Figure 1.

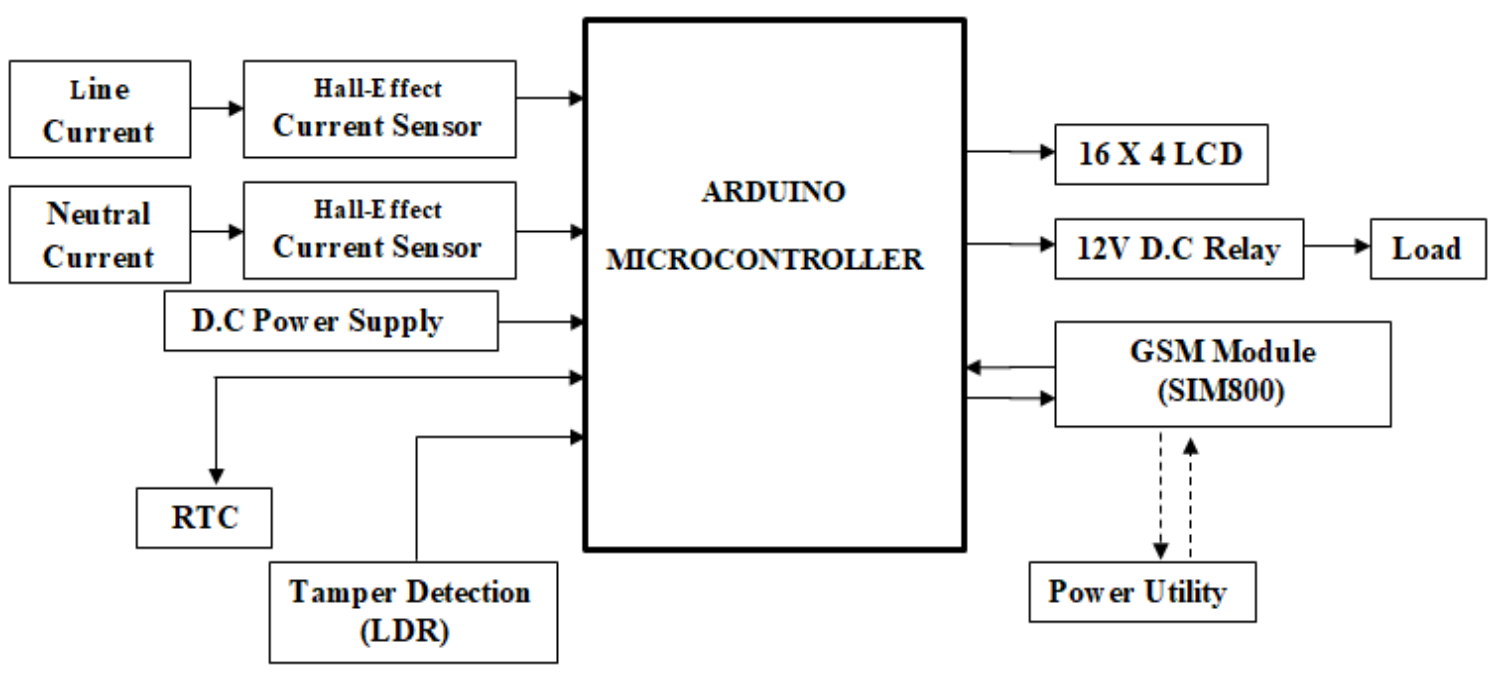

Fig. 1: Block diagram of the smart meter unit

\subsection{Smart Meter Unit}

A microcontroller board was used for computation and control. Also, a voltage and current sensing unit were used to measure the supply voltage and the current drawn from the mains by the consumer's loads, respectively. The voltage sensing unit was connected to analogue pin A0 of the microcontroller while the current sensing unit was connected to analogue pin A2, respectively. The data from these sensors was used to compute power consumption and energy usage. A SIM-800L GSM modem was connected to pins 8 and 9 of the microcontroller to allow serial communication with the GSM module and by extension, the power distribution company. 
A relay was connected to pin 10 of the microcontroller to connect and disconnect the consumer from the mains in the event of energy theft detection or tampering. The consumer will be connected to the mains only when there are no irregularities in the system. In addition, a power supply unit was integrated into the design to power the other parts of the smart metering unit at the required voltages.

\subsection{Communication Channel Unit}

Similar to the other units, a microcontroller board was also used to perform computation and control of the remote. An LCD was connected to pins D4 - D7, 2, and 3 of the microcontroller. The LCD displays information of energy and power consumed, energy and power received from the smart meter unit. A SIM800 GSM Module was connected to pins 8 and 9 of the microcontroller to allow serial communication between the smart meter unit and the power distribution company.

\subsection{Theft Detection Unit}

Two current sensors connected to both live and neutral wires were interfaced respectively to the microcontroller on pins A0 - A2. The block diagram is shown in Fig. 2. Current through live wire denoted as $I_{L}$ and the current through neutral wire denoted as $I_{N}$ are sampled simultaneously; if the difference between $I_{L}$ and $I_{N}$ is greater than a predetermined threshold as in Equation (2) below, then alarm for energy theft is raised; and the highest of the two is used to compute the energy consumed.

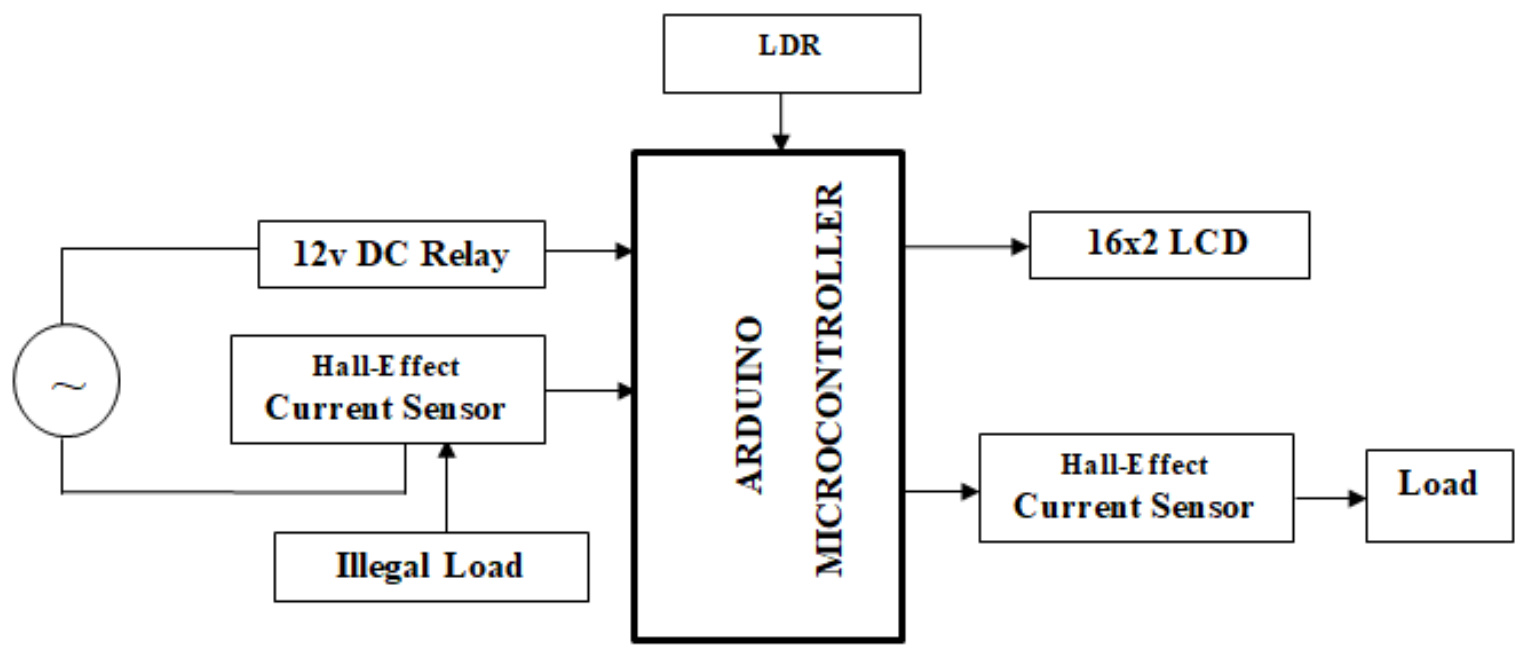

Fig. 2: Energy theft unit 


$$
I_{L}-I_{N}>0.2
$$

Where,

$I_{L}=$ current in live cable

$I_{N}=$ current in neutral cable

And the load current was computed as shown in Equation (3)

$$
I_{r m s}=\sqrt{\frac{1}{N} \sum_{n=1}^{N} I_{n}^{2}}
$$

Where,

$I_{1}, I_{2}, \ldots I_{n}$ are the values of the currents measured by the current sensor at the first, second and up till the $N^{\text {th }}$ sample interval.

A light dependent resistor was connected to pin A6 of the microcontroller to detect tampering on the meter. A relay was connected to pin D12 of the microcontroller to connect and disconnect the consumer from the mains during the occurrence of energy theft on the smart meter. Furthermore, a power supply unit supplies power to the other parts of the units at the required voltages.

\subsection{Simulation of Developed Circuit}

Sequel to hardware construction, simulation was carried out in Proteus 8.6 in order to confirm the feasibility of the design and the performance of developed software. Proteus offers near real time simulation capability for testing embedded systems. Voltage, current and power factor were measured by connecting sinusoidal voltage sources with different rms values and phase angle equivalent to the output from the voltage sensing unit and current sensing unit to the Arduino. The measurement of the smart meter was then compared with the input. The power consumption and energy use of the load was then computed. Theft detection was monitored by comparing the differential between two current sensors reading. Serial communication between the various units of the smart meter was also monitored with Virtual Terminal on Proteus to verify the operation of the remote user interface unit to smart meter and smart meter to utility communications. Disconnecting and connecting of the mains power supply load was simulated by monitoring the state of the microcontroller pins controlling relay and the relay driver. Fig. 3 shows the simulated results and Fig. 4 shows the flowchart of the developed system. 
International Journal of Engineering Technology and Scientific Innovation

ISSN: 2456-1851

Volume: 06, Issue: 04 "July-August 2021"

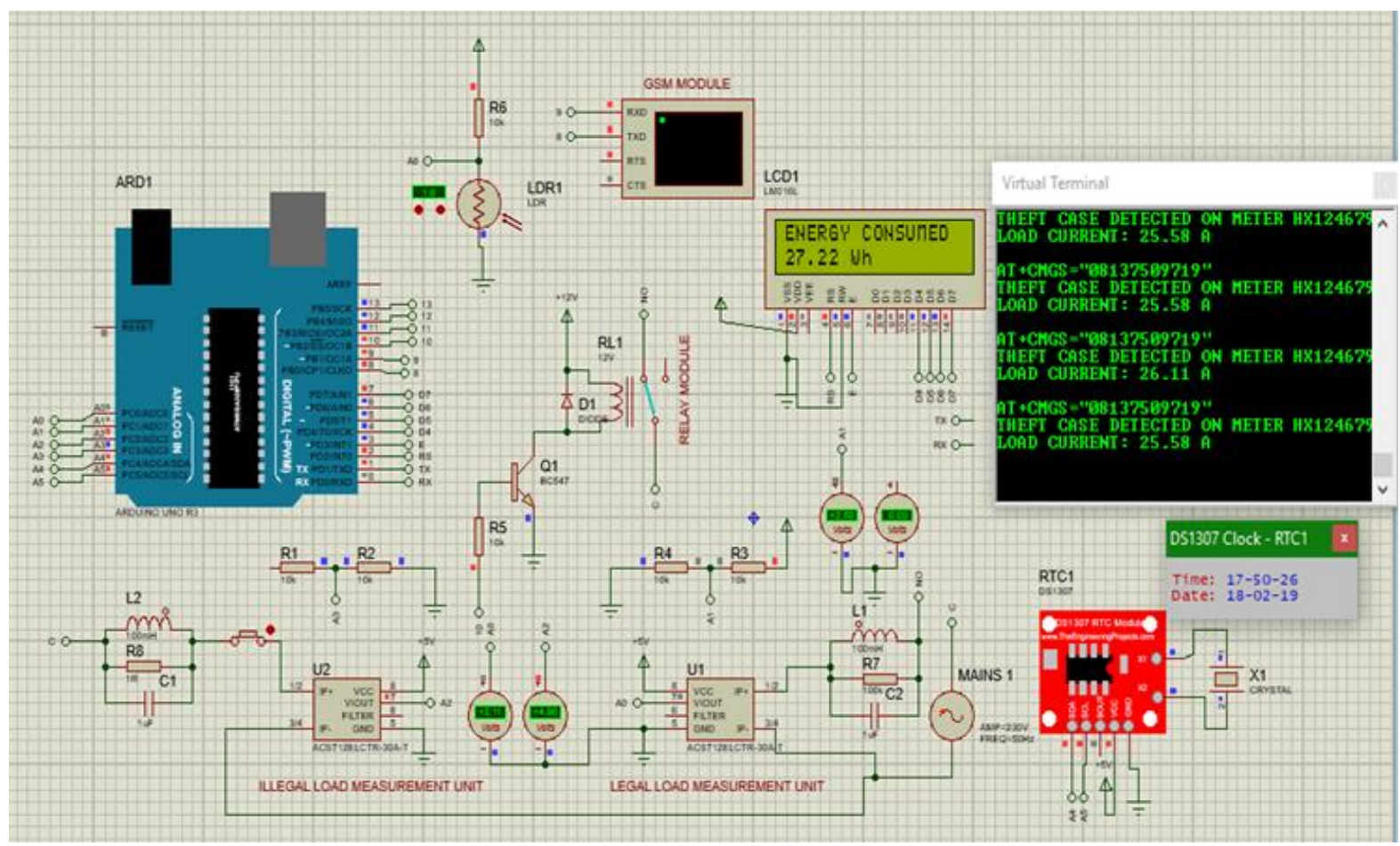

Fig. 3: Simulated system interface 


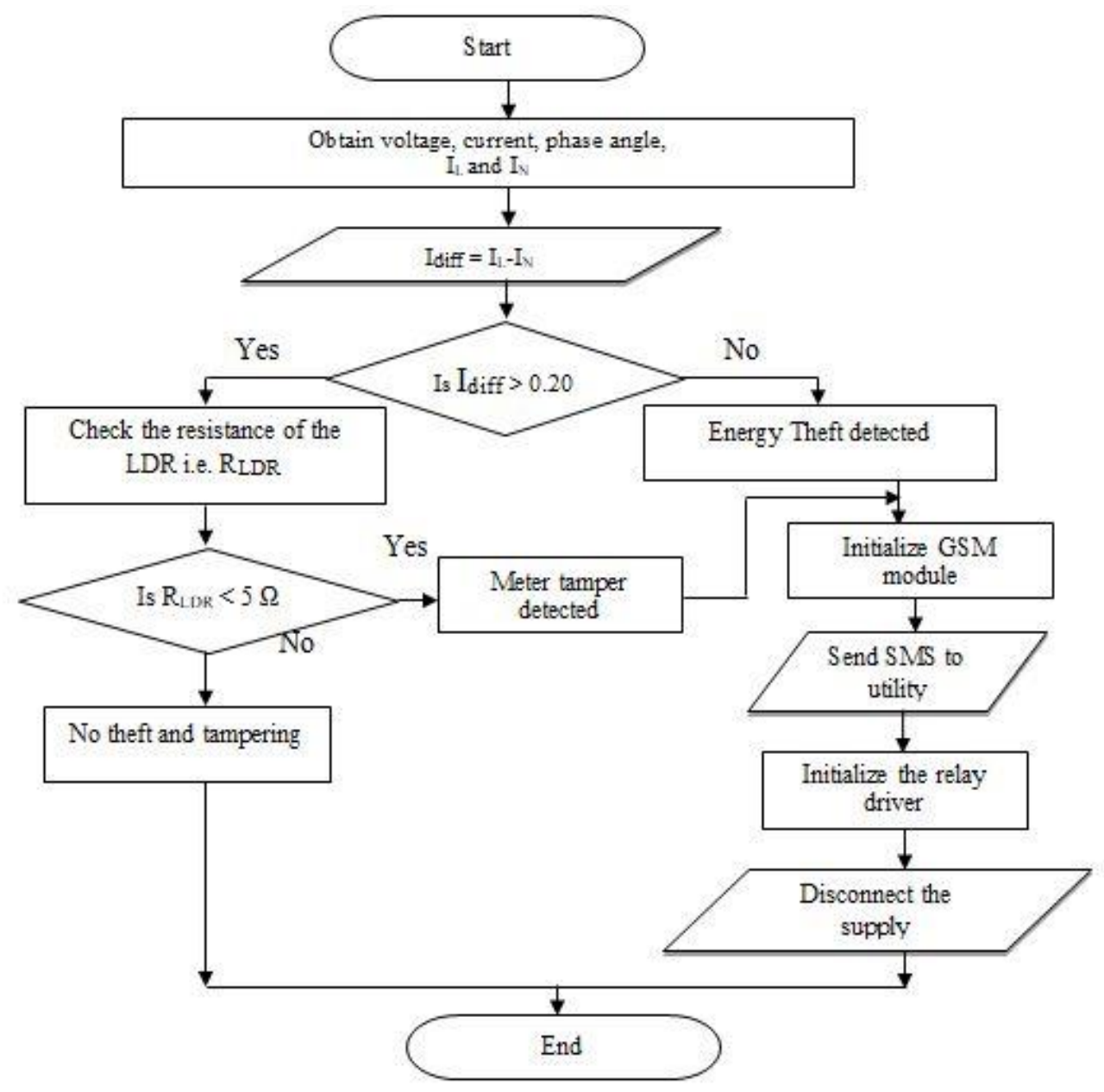

Fig. 4: Flowchart of the developed system

\section{RESULTS AND DISCUSSION}

The smart meter detected energy theft effectively and energy loss was significantly reduced while improving power quality. The energy theft capability of the meter was tested by connecting different loads of varying capacity, giving a system accuracy of $87 \%$. Results obtained using current differential method has been presented. The proposed method therefore proved effective for energy theft detection. The current differential method was implemented and programmed in proteus. The results of the performance of the system were subdivided into different sections depending on the test under consideration.

Tables $1 \& 2$ shows the energy and power measurement results obtained and Figs. $5 \& 6$ shows the power measurement chart and results from the SMS commands. 


\section{International Journal of Engineering Technology and Scientific Innovation}

ISSN: 2456-1851

Volume: 06, Issue: 04 "July-August 2021"

Table 1: Energy measurement

\begin{tabular}{|l|l|c|c|}
\hline \multirow{2}{*}{ Day } & \multicolumn{3}{|c|}{ Smart Meter Reading } \\
\cline { 2 - 4 } & $\begin{array}{c}\text { Energy Reading after } \\
1 \mathrm{hr}(\mathrm{kWh})\end{array}$ & $\begin{array}{c}\text { Energy Reading after } \\
2 \mathrm{hrs}(\mathrm{kWh})\end{array}$ & $\begin{array}{c}\text { Energy Reading after } \\
\text { 3hrs }(\mathrm{kWh})\end{array}$ \\
\hline 1 & 0.054 & 0.107 & 0.161 \\
\hline 2 & 0.154 & 0.307 & 0.461 \\
\hline
\end{tabular}

Table 2: Power measurement test results

\begin{tabular}{|l|c|c|c|}
\hline Load Types & Load Rated Value (W) & Meter Measured Value (W) & Efficiency (\%) \\
\hline Electric Kettle & 1850 & 1600.0 & 86.5 \\
\hline Bread Toaster & 1500 & 1311.0 & 87.4 \\
\hline Electric Cooker & 1000 & 870.0 & 87.0 \\
\hline Boiler Ring & 1000 & 880.0 & 88.0 \\
\hline Electric Iron & 950 & 820.2 & 86.4 \\
\hline Boiler Ring & 500 & 440.0 & 88.0 \\
\hline Incandescent Bulb & 200 & 175.6 & 87.8 \\
\hline Incandescent Bulb & 100 & 87.0 & 87.0 \\
\hline Electric Fan & 70 & 61.1 & 87.3 \\
\hline Incandescent Bulb & 60 & 51.8 & 86.4 \\
\hline Electric Kettle & 1850 & 1600 & 86.5 \\
\hline
\end{tabular}



Fig. 5: Power measurement chart 


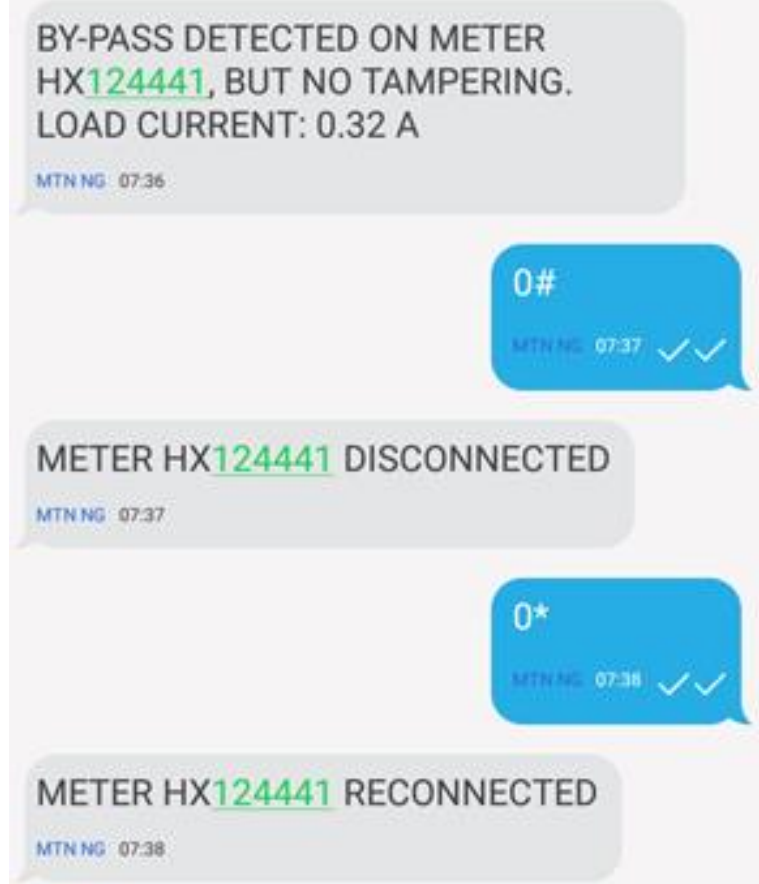

Fig. 6: SMS command

\section{CONCLUSION}

The paper provides an enhanced smart meter for improved electrical distribution system capable of increasing the power distribution company revenue by detecting energy theft using smart metering technology thereby incorporating current differential principle into the system. The developed meter transmits certain information accurately to the power distribution company via GSM communication. The study concluded that the current differential principle is a more effective and efficient method for the detection of energy theft in power distribution system for minimizing energy loss and improving power quality.

\section{REFERENCES}

[1] J. Wang and C. Qi, "The Design of Control System for Smart Meter," IEEE, Computer Society, pp. 1961-1964, 2012.

[2] Nigeria Electricity Regulatory Commission (NERC). Available: https://www.nercng.org/

[3] K. S. K. Weranga, S. Kumarawadu, and D. P. Chandima, Smart Metering Design and Applications. Singapore: Springer Publishers, 2014. 
International Journal of Engineering Technology and Scientific Innovation

ISSN: 2456-1851

Volume: 06, Issue: 04 "July-August 2021"

[4] N. S. Živic, O. Ur-Rehman, and C. Ruland, "Evolution of Smart Metering Systems," 23rd Telecommunications forum (TELFOR), IEEE, pp. 635-638, November 24-26 2015.

[5] R. K. Megalingam, A. Krishnan, B. K. Ranjan, A. K. Nair, A. V. Vidyapeetham, Amritapuri, et al., "Advanced Digital Smart Meter for Dynamic Billing, Tamper Detection and Consumer Awareness," IEEE, pp. 389-393, 2011.

[6] S. S. S. R. Depuru, L. Wang, and V. Devabhaktuni., "Electricity theft: Overview, issues, prevention and a smart meter-based approach to control theft," Elsevier Ltd, pp. 1007$1015,2010$.

[7] M. P. Manojkumar, R. M. Prasanna, L. Shakti, S. Sneha, and U. Chandrakant, "GSM Based Power Theft Detection System Using Android," International Journal of Engineering Science and Computing (IJESC), vol. 6, pp. 6016-6018, May 2016.

[8] D. O. Dike, U. A. Obiora, E. C. Nwokorie, and B. C. Dike, "Minimizing Household Electricity Theft in Nigeria Using GSM Based Prepaid Meter," American Journal of Engineering Research (AJER), vol. 4, pp. 59-69, January 2015.

[9] S. Sardar and S. Ahmad, "Detecting and Minimizing Electricity Theft: A Review," November 2016.

[10] M. Nabil, B. Anomadarshi, and A. A. Muhammad, "A Smart Prepaid Energy Metering System to Control Electricity Theft," IEEE, pp. 562-565, 2013.

[11] P. Sharma, H. Gupta, M. Sharma, R. Singh, and A. Khan, "Wireless Electricity Theft Detection and Monitoring," International Journal of Advanced Research in Electronics and Communication Engineering (IJARECE), vol. 5, pp. 994-998, April 2016.

[12] K. Anil, b. prashanth, and A. Saurabh, "Design and Implementation of Wireless Energy Meter System for Monitoring the Single-Phase Supply," International Journal of Computer Applications, vol. 41, pp. 26-29, March 2016.

[13] S. Anshul, I. Patel, S. Axat, and D. Anuradha, "Tampering Detection of Energy Meter by GSM Modem," International Journal of Engineering Innovation \& Research (IJEIR), vol. 4, pp. 433-440, 2015.

[14] J. V. Wijayakulasooriya, D. M. Dasanayake, P. I. Muthukumarana, and L. A. Thelisinghe, "Remotely Accessible Single-Phase Energy Measuring System," 1st International Conference on Industrial andInformation Systems, IEEE, pp. 304-309, 2006. 
International Journal of Engineering Technology and Scientific Innovation

ISSN: 2456-1851

Volume: 06, Issue: 04 "July-August 2021"

[15] A. Pasdar and S. Mirzakuchaki, "A Solution to Remote Detecting of Illegal Electricity Usage Based on Smart Metering," IEEE 2nd Int'l workshop on Soft Computing Applications pp. 163-167, 2007.

[16] S. Patil, G. Pawaskar, and K. Patil, "Electrical Power Theft Detection and Wireless Meter Reading," International Journal of Innovative Research in Science, Engineering and Technology, vol. 2, pp. 1114-1119, April 2013. 